\title{
Acknowledgements to JINS Guest Editors and External Reviewers, 2016
}

The success of JINS as a scientific journal depends on thoughtful, honest, and prompt peer review. Such review would be impossible without the extensive help of colleagues. Dr. Rao and his Associate Editors are grateful to the selfless contributions of our Board of Consulting Editors, guest editors and principal, ad-hoc, and student reviewers. The following lists include individuals who contributed between December 1, 2015 and November 30, 2016. Please note that, because of timing issues, a reviewer's name might not appear in this year's list either because s/he was acknowledged in a previous year or will be acknowledged in the forthcoming year.

The following is a list of guest editors:

Mark Bondi Deborah Harrington

The following is a list of Principal Reviewers, who reviewed a substantial number of manuscripts for the 2016 volume:

$\begin{array}{ll}\text { Melissa Amick } & \text { Brandon Gavett } \\ \text { Paul Brewster } & \text { Brenda Hanna-Pladdy } \\ \text { Rachel Buckley } & \text { Gregory Kroliczak } \\ \text { Mark Ettenhofer } & \text { Glenn Larrabee } \\ \text { Joanne Fielding } & \text { Eric Larson }\end{array}$

Katherine Possin

Johannes Rothlind

Rene Stolwyk

Julie Suhr

The following is a list of Ad-Hoc Reviewers for the 2016 volume:

$\begin{array}{lll}\text { Tatiana Aboulafia Brakha } & \text { Nicole Barcelos } & \text { Gerald Bruder } \\ \text { Marilena Aiello } & \text { Deanna Barch } & \text { Giovanni Buccino } \\ \text { Olusola Ajilore } & \text { Morgan Barense } & \text { Annemieke Buizer } \\ \text { Omar Alhassoon } & \text { Lisa Barnes } & \text { Katherine Burdick } \\ \text { Phil Allen } & \text { William Barr } & \text { William Burns } \\ \text { Laura Alonso-Recio } & \text { Michael Basso } & \text { Desiree Byrd } \\ \text { Bara Alsalaheen } & \text { Christine Bastin } & \text { Elise Caccappolo } \\ \text { Lori Altmann } & \text { Thomas Baumann } & \text { Carolyn Caldwell } \\ \text { Elisabetta Ambron } & \text { Dean Beebe } & \text { Michael Caligiuri } \\ \text { Jodie Ambrosino } & \text { Heather Belanger } & \text { Pablo Campo } \\ \text { Ross Andel } & \text { Anya Benitez } & \text { Michael Cannizzaro } \\ \text { Peter Anderson } & \text { Thomas Benke } & \text { Kaitlin Casaletto } \\ \text { Peter Anderson } & \text { Andrea Berger } & \text { Richard Caselli } \\ \text { Cay Anderson-Hanley } & \text { David Beversdorf } & \text { Larry Cashion } \\ \text { Stein Andersson } & \text { Nathalie Bier } & \text { Adam Cassidy } \\ \text { Sophie Andrews } & \text { Laurence Binder } & \text { Brian Castelluccio } \\ \text { Andrea Antal } & \text { Gabriëlla Blokland } & \text { M. Allison Cato Jackson } \\ \text { Anne Arnett } & \text { Lee Blonder } & \text { Samuel Chamberlain } \\ \text { Andrew Aschenbrenner } & \text { Igor Bombin } & \text { Dorota Chapko } \\ \text { Rhoda Au } & \text { Kyle Boone } & \text { Annabel Chen } \\ \text { John Aucott } & \text { Erika Borella } & \text { Shawn E. Christ } \\ \text { Robin Aupperle } & \text { Robert Bornstein } & \text { Foteini Christidi } \\ \text { Sara Aurtenetxe } & \text { Andrew Bowers } & \text { Christopher Christodoulou } \\ \text { Alex Bahar-Fuchs } & \text { Yvonne Brehmer } & \text { Kai-Hsiang Chuang } \\ \text { Amber Bahorik } & \text { Lisa Brenner } & \text { Elisa Ciaramelli } \\ \text { Juliana Baldo } & \text { Brian Brooks } & \text { Cynthia Cimino } \\ \text { David Balota } & \text { Pim Brouwers } & \text { Uraina Clark }\end{array}$




\author{
Derin Cobia \\ Ronald Cohen \\ Melanie Cohn \\ Jessica Collins \\ Lorenza Colzato \\ Hannah Combs \\ Ciaran Considine \\ Nathan Cook \\ Alberto Costa \\ James Coxon \\ Kristen Dams-O'Connor \\ Warren Darling \\ Nicholas Davenport \\ Patrick Davidson \\ Jeremy Davis \\ Miet De Letter \\ Anik De Ribaupierre \\ Mattieu De Wit \\ Rebecca Deason \\ Joseph DeGutis \\ Leon Deouell \\ Genevieve Desmarais \\ Georg Dirnberger \\ Ekaterina Dobryakova \\ Jacobus Donders \\ Vonetta Dotson \\ N Dowling \\ Janet Duchek \\ Kevin Duff \\ John Duncan \\ Moira Dux \\ Deborah Eakin \\ Nicola Edelstyn \\ Emily Edmonds \\ Randi Eikland \\ Merrill Elias \\ Timothy Ellmore \\ Kristi Erdal \\ Laszlo Erdodi \\ Jonathan Evans \\ Lisa Eyler \\ Eric Fakra \\ Sean Fallon \\ Bryan Fantie \\ Philip Fastenau \\ George Fein \\ Leonardo Fernandino \\ Richard Ferraro \\ Jamie Feusner \\ Carsten Finke \\ Scott Fish \\ Jack Fletcher \\ Rochele Fonseca \\ Emilie Fortier-Brochu \\ Sarah Fraser \\ Augusto Fusco \\ Adolfo Garcia
}

\begin{tabular}{|c|c|}
\hline Bruno Gauthier & Lisa Jacola \\
\hline Helen Genova & Amy Jak \\
\hline Gwendolyn Gerner & Lorna Jakobson \\
\hline Adam Gerstenecker & Nathaniel James \\
\hline Wim Gevers & Steven Jax \\
\hline Paul Gilbert & David Jenson \\
\hline Tania Giovannetti & Julene Johnson \\
\hline Todd Girard & Elizabeth Johnson \\
\hline Cheryl Glazebrook & Doug Johnson-Greene \\
\hline Yifat Glikmann-Johnston & Brick Johnstone \\
\hline David Gold & Christian Joyal \\
\hline Elkhonon Goldberg & Tedd Judd \\
\hline Georg Goldenberg & Carme Junqué \\
\hline Felicia Goldstein & Elke Kalbe \\
\hline Dave Gonzalez & Irene Kan \\
\hline Linda Gonzalez & Mindy Katz \\
\hline Diane Gooding & Gitit Kavé \\
\hline Madeleine Goodkind & Angie Kehagia \\
\hline Yael Goverover & David Kemmerer \\
\hline Daniel Greenberg & Richard Kennedy \\
\hline Jennifer Greenberg & Robert Kern \\
\hline Matthew Grilli & Ronald Killiany \\
\hline Ellen Grober & Alice Kim \\
\hline Sarah Gunnery & Glynda Kinsella \\
\hline Tjerk Gutteling & Michael Kirkwood \\
\hline Christian Habeck & Benzi Kluger \\
\hline Andreana Haley & Piyadasa Kodituwakku \\
\hline Ilona Hallikainen & Joshua Koen \\
\hline John Hart & Kostas Konstantopoulos \\
\hline Lynn Hasher & Jennifer Koop \\
\hline Misty Hawkins & Danny Koren \\
\hline Jasmeet Hayes & Rebecca Koscik \\
\hline Daniel Hermens & Mary Kosmidis \\
\hline Joachim Hermsdörfer & Kevin Krull \\
\hline Christopher Hertzog & Jaime Kulisevsky \\
\hline Robert Hester & Fiona Kumfor \\
\hline John Hindle & Guilherme Lage \\
\hline Charles Hinkin & Amit Lampit \\
\hline Matthew Hocking & Dawn Langdon \\
\hline Timothy Hohman & Daman Langguth \\
\hline James Holdnack & Michael Larson \\
\hline Alice Ann Holland & Jacqueline Laures-Gore \\
\hline Roee Holtzer & Michal Lavidor \\
\hline Dan Hoofien & M Lavoie \\
\hline Michael Horner & Andrew Lawrence \\
\hline Kristen Hoskinson & Blake Lawrence \\
\hline James Howard & Pam Leavenex \\
\hline William $\mathrm{Hu}$ & Victoria Leavitt \\
\hline Anita Hubley & Joseph Lee \\
\hline Gizem Hueluer & Junghee Lee \\
\hline Julian Hughes & Deborah Levy \\
\hline Stacey Humphries & Chris Lewis \\
\hline Jinyi Hung & Matthew Lewis \\
\hline Scott Hunter & Kirsten Lindquist \\
\hline Naroa Ibarretxe-Bilbao & Tara Lineweaver \\
\hline Muireann Irish & Angelika Lingnau \\
\hline Mark Jacobson & Hester Lingsma \\
\hline
\end{tabular}




\begin{tabular}{|c|c|c|}
\hline Alexander Lischke & Annie New & Maegan Sady \\
\hline Deborah Little & Julie Newman & Arnaud Saimpoint \\
\hline Teresa Liu-Ambrose & Mary Newsome & David Salat \\
\hline Gianna Locascio & T. Rune Nielsen & Cynthia Salorio \\
\hline Martin Lotze & Tomas Nikolai & Brian Sandroff \\
\hline Hanna Lu & Sara Nixon & Kayle Sawyer \\
\hline Angela Lukowski & Margaret Niznikiewicz & Federica Scarpina \\
\hline Noortje Maaijwee & Progress Njomboro & Lynn Schaefer \\
\hline William MacAllister & Ugo Nocentini & Philip Schatz \\
\hline Anil Malhotra & Kyle Noll & Randall Scheibel \\
\hline Lilianne Manning & Nancy Nussbaum & Dawn Schiehser \\
\hline Amy Margolis & Liesl Nydegger & Katharina Schnitzspahn \\
\hline Camillo Marra & Emmanuel Ojo & Jane Schreiber \\
\hline Rebecca Marshall & Stephanie Oleson & Ricarda Schubotz \\
\hline Eileen Martin & Joukje Oosterman & Ilse Schuitema \\
\hline Markus Martin & Katherine Osborne-Crowley & Lars Schulze \\
\hline Sarah Martindale & François Osiurak & Randi Schuster \\
\hline Anthony Martyr & Akira Osone & Carolyn Schwartz \\
\hline Brian Marx & Luz Ospina & Emma Sciberras \\
\hline Bilal Mateen & Jaya Padmanabhan & Fiona Scott \\
\hline James McAuley & Ming-Chyi Pai & Michael Scullin \\
\hline Shawn McClintock & Daniela Palombo & Anna Sedda \\
\hline Jane McDevitt & Lawrence Parsons & Paula Shear \\
\hline Brenna McDonald & Thomas Parsons & Signy Sheldon \\
\hline Craig McFarland & Nicholas Pastorek & Mark Sherer \\
\hline Jessica McGovern & Sunita Patel & Arthur Shores \\
\hline Lauren McGrath & Friedemann Paul & Mattia Siciliano \\
\hline Susan McGurk & Mariella Pazzaglia & Tamar Silberg \\
\hline Peter McKenna & Roberta Perri & Noah Silverberg \\
\hline Audrey McKinlay & Robin Peterson & Sharon Simon \\
\hline Donald McLaren & Dwight Peterson & Tatiana Sitnikova \\
\hline Susanne Meares & Jeffrey Philips & Gary Small \\
\hline Emmanuel Mellet & Laura Phillips & MaryLou Smith \\
\hline Cláudia Memória & Olivier Piguet & Megan Smith \\
\hline Francesca Meneghello & Kerryn Pike & Beth Snitz \\
\hline Simone Messerotti Benvenuti & Daniel Poole & Christina Sobin \\
\hline Maarten Milders & Catherine Price & Anja Soldan \\
\hline L. Miller & Jenny Rabin & Chandler Sours \\
\hline Scott Millis & Amanda Rabinowitz & Gianfranco Spalletta \\
\hline Irene Minkina & J. Daniel Ragland & Gershon Spitz \\
\hline Maria Misiura & Jennifer Randerath & Mary Beth Spitznagel \\
\hline Meghan Mitchell & Sarah Raskin & Beth Springate \\
\hline Malek Mneimne & Sarah Raz & Desiree Spronk \\
\hline Daniela Montaldi & Jill Razani & Vessela Stamenova \\
\hline Benedetta Monzani & Elizabeth Reese & Craig Stark \\
\hline Hugo Morais & Hannah Reese & Peter Stavinoha \\
\hline Erin Morgan & Louis Renoult & Karina Stavitsky \\
\hline Katy Mueller & Dorene Rentz & Glenn Stebbins \\
\hline Kelly Murphy & Corrin Richels & Hana Stepankova \\
\hline Catherine Myers & M. Ris & Robert Stern \\
\hline Stephen Nadeau & Monica Rivera Mindt & Christopher Stewart \\
\hline Samuel Nastase & Martin Rohling & Nikki Stricker \\
\hline Dominic Nathan & Daniel Romer & Lauren Strober \\
\hline Daniel Nation & James Root & Virginia Sturm \\
\hline Nathaniel Nelson & Allyson Rosen & Michael Sugarman \\
\hline Michael Nester & Donald R. Royall & Michael Sullivan \\
\hline Andres Neuhaus & Umberto Sabatini & Preeti Sunderaraman \\
\hline
\end{tabular}


Jerry Sweet

Lawrence Sweet

Amanda Szabo

Vanessa Taler

Reem Tarazi

H. Gerry Taylor

Nancy Temkin

Elena Tenconi

Michael Thomas

David Thornton

Wendy Thornton

Ivan Torres

Joey Trampush

Amery Treble-Barna

Geoffrey Tremont

Lyn Turkstra

Travis Turner

Wery Van Den Wildenberg

Ineke Van Der Ham

Ellen Van Der Plas

Tamsyn Van Rheenen

Dorien Vandenborre

Susan Vandermorris

Diana VanLancker Sidtis
Eleftheria Vaportzis
Jennifer Vasterling
Christopher Vaughan
Diana Velikonja
Paul Verhaeghen
Steven Verheyen
Laura Veronelli
Carmelo Vicario
Javier Virues-Ortega
Evy Visch-Brink
Pieter Jelle Visser
Alecia Vogel
Stephanie Vos
Michael Wagner
Karin Walsh
Rachel Wasserman
Bruce Wexler
Anneli Wheeler
Douglas Whiteside
Lynne Williams
Claire Williams
Victoria Williams

Diana VanLancker Sidtis

Jennifer Vasterling

Christopher Vaughan

Diana Velikonja

Paul Verhaeghen

Steven Verheyen

Laura Veronelli

Carmelo Vicario

Javier Virues-Ortega

Evy Visch-Brink

Pieter Jelle Visser

Alecia Voge

Stephanie Vos

Michael Wagne

Rachel Wasserman

Bruce Wexler

Anneli Wheeler

Douglas Whiteside

Claire Williams

\author{
John Williamson \\ Ericka Wodka \\ Adrian Wong \\ Kristen Woodberry \\ Steven Paul Woods \\ Neil Woodward \\ Andrew Worthington \\ Jeffrey Wozniak \\ Kathryn Wyman-Chick \\ Christie Yao \\ Michael Yassa \\ Ronald Yeo \\ Brian Yochim \\ Jeremy Young \\ Kovas Yulia \\ T. Zabel \\ Konstantine Zakzanis \\ Giandaniele Zannino \\ Laura Zapparoli \\ Hui Zhang \\ Molly Zimmerman
}

Beginning in 2014, the JINS student reviewer mentorship program was initiated. The following list comprises students who conducted manuscript reviews in 2016 under the tutelage of their mentor (listed in parentheses):

\author{
Elizabeth Altman (Cay \\ Anderson-Hanley) \\ Zachariah Arnold (Cay \\ Anderson-Hanley) \\ Matt Bagg (James McAuley) \\ Hugo Baggio (Carme Junqué) \\ John Best (Teresa Liu-Ambrose) \\ Sagarika Bhattacharjee (Annabel Chen) \\ Brian Biekman (Harvey Levin) \\ Cara Bussell (Brandon Gavett) \\ Margaret Cadden (Peter Arnett) \\ Marina Cavuoto (Kerryn Pike) \\ Caroline Champagne (Bruno Gauthier) \\ Ashley Clausen (Robin Aupperle) \\ Ciaran Considine (Thomas Hammeke) \\ Ciaran Considine (Eric Larson) \\ Stephany Cox (Karin Walsh) \\ Kristin Crocfer (Lisa Jacobson) \\ Flavia De Luca (Elisa Ciaramelli) \\ Amelia Denney (Cay \\ Anderson-Hanley) \\ Haley Duncanson (Dorene Rentz) \\ Jeremy Elman (Lisa Eyler) \\ Ashley Fournier-Goodnight \\ (Heather Conklin) \\ Sarah Garcia (Benjamin Hampstead)
}

Anna Graefe (Johannes Rothlind)

Jessica Green (Emma Sciberras)

Jason Griffin (Brandon Gavett)

Erin Guty (Peter Arnett)

Emily Hallowell (Lawrence Sweet)

Megan Harrelson (Hugo Morais)

Yael Holzman (Andrea Berger)

Karolina Horakova (Hana Stepankova)

Jacob Hulswit (Tania Giovannetti)

Shivangi Jain (Paul Verhaeghen)

Erica Kornblith (Johannes Rothlind)

Agnieszka Kubiak (Gregory

Kroliczak)

Taylor Kuhn (Charles Hinkin)

Stephanie Leal (Michael Yassa)

Jackson Liang (Morgan Barense)

Olaia Lucas-Jiménez (Naroa

Ibarretxe-Bilbao)

Maxime Lussier (Nathalie Bier)

Saül Martinez-Horta (Jaime

Kulisevsky)

Mark McCurdy (Matthew Hocking)

Katalina McInerney (Bonnie Levin)

Adam Mickiewicz (Gregory

Kroliczak)

Danielle Miller (Jasmeet Hayes)
Shawn Nelson-Schmitt (Mark

Ettenhofer)

Madison Niermeyer (Yana Suchy)

Nwana Ola-Edo (Megan Smith)

Rachel Peterson (Heather Conklin)

Jean Patrick Phillipe Scheib (Jennifer Randerath)

Vickie Plourde (Brian Brooks)

Deepti Putcha (Geoffrey Tremont)

Megan Reif (Allyson Rosen)

Katherine Reiter (Kristy Nielson)

Isabela Sallum Guimarães (Leandro Malloy-Diniz)

Jessica Saurman (Brandon Gavett)

Kerri Scorpio (Joan Borod)

Marsha Siebenmorgen (Jennifer Koop)

Kimberly Skillicorn (T. Andrew Zabel)

David Skvarc (Matthew Lewis)

Dana Szeles (Anya Benitez)

Alvin Ting Fang Ang (Rhoda Au)

Sally Vogel (Michael Parsons)

Jennifer Weeks (Lynn Hasher)

Lauren Weiss (J. Carson Smith)

Emily West (Cay Anderson-Hanley)

Stephanie Wong (Muireann Irish)

Jennifer Yuan (Roee Holtzer) 
Aims and Scope The Journal of the International Neuropsychological Society is the official journal of the International Neuropsychological Society, an organization of over 4,500 international members from a variety of disciplines. The Journal of the International Neuropsychological Society welcomes original, creative, high quality research papers covering all areas of neuropsychology. The focus of articles may be primarily experimental, applied, or clinical. Contributions will broadly reflect the interest of all areas of neuropsychology, including but not limited to: development of cognitive processes, brain-behavior relationships, adult and pediatric neuropsychology, neurobehavioral syndromes (such as aphasia or apraxia), and the interfaces of neuropsychology with related areas such as behavioral neurology, neuropsychiatry, genetics, and cognitive neuroscience. Papers that utilize behavioral, neuroimaging, and electrophysiological measures are appropriate.

To assure maximum flexibility and to promote diverse mechanisms of scholarly communication, the following formats are available in addition to Regular Research Articles: Brief Communications are shorter research articles; Rapid Communications are intended for "fast breaking" new work that does not yet justify a full length article and are placed on a fast review track; Neurobehavioral Grand Rounds are theoretically important and unique case studies; Critical Reviews and Short Reviews are thoughtful considerations of topics of importance to neuropsychology, including associated areas, such as functional brain imaging, genetics, neuroepidemiology, and ethical issues; Dialogues provide a forum for publishing two distinct positions on controversial issues in a pointcounterpoint format; Symposia consist of several research articles linked thematically: Letters to the Editor respond to recent articles in the Journal of the International Neuropsychological Society; and Book Reviews. Critical Reviews, Dialogues, and Symposia are typically invited by the Editor-in-Chief or an Associate Editor. Book Reviews are considered but are no longer solicited.

Originality and Copyright To be considered for publication in the Journal of the International Neuropsychological Society, a manuscript cannot have been published previously nor can it be under review for publication elsewhere. Papers with multiple authors are reviewed with the assumption that all authors have approved the submitted manuscript and concur with its submission to the Journal of the International Neuropsychological Society. A Copyright Transfer Agreement, with certain specified rights reserved by the author, must be signed and returned to the Editor-in-Chief by the corresponding author of accepted manuscripts, prior to publication. This is necessary for the wide distribution of research findings and the protection of both author and the society under copyright law. If you plan to include material that has been published elsewhere and is under copyright of a third party, you will need to obtain permission to re-use this material in your article. A form may be provided for this purpose by the editorial office. Alternatively, many publishers use an online system for such requests. It is the responsibility of the authors to obtain permissions to re-use material from elsewhere. For information regarding rights and permissions concerning the Journal of the International Neuropsychological Society, please contact Marc Anderson (manderson@ cambridge.org) or Adam Hirschberg (ahirschberg@ cambridge.org)

Disclosure Potential conflicts of interest include funding sources for the reported study (e.g., a test validation study financially supported by a test publisher, a study supported by an insurance company), personal or family financial interest in a test or product or with a company that publishes a test that is being investigated in the manuscript or competes with a test that is being investigated in the manuscript. Other conflicts include employment, consultancies, stock ownership or medicolegal work. For the latter, information about whether the author's medicolegal work is largely for one side should be reported. This list of potential conflicts is not all inclusive, and it is the responsibility of each author to ensure that all of their "potential conflicts" are reported in the Acknowledgment section of the paper.

Disclosure pertains to all authors. It is the corresponding author's ethical responsibility to explicitly check with each of his/her co-authors to ensure that any real or apparent conflict of interest is appropriately disclosed. Authors should err on the side of full disclosure, and if authors are uncertain about what constitutes a relevant conflict, they should contact the editorial office jins@cambridge.org. The intent of this disclosure is not to prevent an author with a significant financial or other relationship from publishing their work in the Journal of the International Neuropsychological Society, but rather to provide readers with adequate information to form their own judgments about the work.

Compliance with institutional research standards for animal or human research (including a statement that the research was completed in accordance with the Helsinki Declaration (http://www.wma.net/en/ 30publications/10policies/b3/) should be included in the methods section of the manuscript.

Manuscript Submission and Review The Journal of the International Neuropsychological Society uses online submission and peer review. Paper submissions are not accepted. Authors who are not able to submit their manuscripts online are asked to contact the editorial office at: jins@cambridge.org. The website address for submissions is http://mc.manuscriptcentral.com/cup/jins; complete instructions are provided on the website. Prior to online submission, please consult http:// www.nlm.nih.gov/mesh/ for 6 keywords or mesh terms that are different from words in the title. Accurate mesh terms will increase the probability that your manuscript will be identified in online searches. Please follow the instructions carefully to avoid delays. The menu will prompt the author to provide all necessary information, including the manuscript category, the corresponding author including postal address, phone and fax numbers, and e-mail address, and suggested reviewers.

The website will automatically acknowledge receipt of the manuscript and provide a manuscript reference number. The Editor-in-Chief will assign the manuscript for review to an action editor and at least two other reviewers. Every effort will be made to provide the author with a review within 6 to 10 weeks of manuscript assignment. Rapid Communications will be reviewed within 6 weeks. If the Editor requests that revisions be made to a manuscript before publication, a maximum of 3 months will be allowed for preparation of the revision, except in unusual circumstances.

Manuscript Length In order to increase the number of manuscripts that can be published in the Journal of the International Neuropsychological Society, please adhere to the following length requirements. Please provide a word count on the title page for the abstract and manuscript (not including abstract, tables, figures, or references). Manuscripts will be returned if they exceed length requirements
Regular Research Article: Maximum of 5,000 words (not including abstract, tables, figures, or references) and a 250 word abstract. Regular Research Articles are original, creative, high quality papers covering all areas of neuropsychology; focus may be experimental, applied or clinical.

Brief and Rapid Communications: Maximum of 2,500 words (not including abstract, tables, figures, or references) and a 200 word abstract, with a maximum of two tables or two figures, or one table and one figure, and 20 references. Brief and Rapid Communications are shorter research articles.

Case Reports: Maximum of 3,500 words with an informative literature review (not including abstract, tables, figures, or references) and a 200 word abstract. Unique case studies that make a significant theoretical contribution.

Critical Review: Maximum of 7,000 words (not including abstract, tables, figures, or references) and a 250 word abstract. Critical Reviews will be considered on any important topic in neuropsychology. Quantitative meta-analyses are encouraged. Critical Reviews must be preapproved by the Editor-in-Chief. For consideration, please e-mail your abstract to jins@ cambridge.org.

Short Review: Maximum of 2,500 words (not including abstract, tables, figures, or references) and a 150 word abstract. Short Reviews are conceptuallyoriented snapshots of the current state of a research area by experts in that area. Short Reviews must be preapproved by the Editor-in-Chief. For consideration, please e-mail your abstract to jins@cambridge. org.

Dialogues: Maximum of 2,000 words for each segment (not including abstract, tables, figures, or references) and a 150 word abstract, with a maximum of two tables or two figures, or one table and one figure and 20 references. Dialogues provide a forum for two distinct positions on controversial issues in a point-counterpoint form. Dialogues must be preapproved by the Editor-in-Chief. For consideration, please e-mail your abstract to jins@cambridge.org.

Symposia: Maximum of 5,000 words (not including abstract, tables, figures, or references) and a 250 word abstract for each article (same as Regular Research Articles). Symposia consist of several thematically linked research articles which present empirical data. Symposia must be pre-approved by the Editorin-Chief. For consideration, e-mail your proposal to jins@cambridge.org to receive prior approval.

Letters to the Editor: Maximum of 500 words (not including table, figure, or references) with up to five references and one table or one figure. Letters to the Editor respond to recent articles in Journal of the International Neuropsychological Society.

Book Reviews: Maximum of 1000 words in length. Include name and affiliations, a title for the review, the author(s)/editor(s), title, publisher, date of publication, number of pages and price. For consideration, e-mail jins@cambridge.org.

Manuscript Preparation and Style The entire manuscript should be typed double-spaced throughout using a word processing program. Unless otherwise specified, the guideline for preparation of manuscripts is the Publication Manual of the American Psychological Association (6th edition) except for references with 3 or more authors (see References section). This manual may be ordered 
from: APA Order Dept., 750 1st St. NE, Washington, DC 20002-4242, USA.

Pages should be numbered sequentially beginning with the Title Page. The Title Page should contain the full title of the manuscript, the full names and institutional affiliations of all authors; mailing address, telephone and fax numbers, and e-mail address for the corresponding author; and the word count for the abstract and manuscript text (excluding title page, abstract, references, tables, and figures). At the top right provide a short title of up to 45 characters preceded by the lead author's last name. Example: Smith-Memory in Parkinson's Disease. This running head should be repeated at the top right of every following page.

Page 2 should include an Abstract and a list of at least six keywords or mesh terms. Note: structured abstracts must be included with papers submitted after January 1, 2014. A structured abstract must include four header labels: Objective, Method, Results, and Conclusions. A total of six mesh terms (http://www.nlm.nih.gov/mesh/) or keywords should be provided and should not duplicate words in the title.

The full text of the manuscript should begin on page 3. For scientific articles, including Regular Research Articles, Brief Communications, Rapid Communications, and Symposia, the format should include a structured Abstract, Introduction, Method, Results, and Discussion. This should be followed by Acknowledgments, References, Tables, Figure Legends, Figures, and optional Appendices and Supplemental Material.

The use of abbreviations, except those that are widely used, is strongly discouraged. They should be used only if they contribute to better comprehension of the manuscript. Acronyms should be spelled out at first mention. Metric system (SI) units should be used.

Appendices and Supplemental Materials may be submitted. Appendices include material intended for print and should be included with the manuscript file. Supplementary material will appear only online and should be submitted as a separate file.

The Acknowledgements Section should include a disclosure of confiicts of interest (see above) and all sources of financial support for the paper. In documenting financial support, please provide details of the sources of financial support for all authors, including grant numbers. For example, "This work was supported by the National Institutes of Health (grant number XXXXXXX)". Multiple grant numbers should be separated by a comma and space and where research was funded by more than one agency, the different agencies should be separated by a semicolon with "and" before the final funding agency. Grants held by different authors should be identified using the authors' initials. For example, "This work was supported by the Wellcome Trust (A.B., grant numbers XXXX, YYYY), (C.D., grant number ZZZZ); the Natural Environment Research Council (E.F., grant number FFFF); and the National Institutes of Health (A.B., grant number GGGG), (E.F., grant number $\mathrm{HHHH}) . "$

Tables and Figures should be numbered in Arabic numerals. Figures should be numbered consecutively as they appear in the text. Figures should be twice their intended final size and authors should do their best to construct figures with notation and data points of sufficient size to permit legible photo reduction to one column of a two-column format.

Please upload figure(s) in either a .doc or .pdf format. There is no additional cost for publishing color figures. When uploading figures (color or black and white) they need only be a high enough resolution for the reviewers and editors to identify the information you are trying to convey.

The approximate position of each table and figure should be provided in the manuscript: [INSERT TABLE 1 HERE]. Tables and figures should be on separate pages. Tables should have short titles and all figure legends should be on separate pages.

References should be consistent with the Publication Manual of the American Psychological Association (6th Edition). In-text references should be cited as follows: "... Given the critical role of the prefrontal cortex (PFC) in working memory (Cohen et al., 1997; Goldman-Rakic, 1987; Perlstein et al., 2003a, 2003b) ..." with multiple references in alphabetical order. Another example: “...Cohen et al. (1994, 1997), Braver et al. (1997), and Jonides and Smith (1997) demonstrated ..." References cited in the text with two authors should list both names. References cited in the text with three, four, or five authors, list all authors at first mention; with subsequent citations, include only the first author's last name followed by et al. References cited in the text with six or more authors should list the first author et al. throughout. In the reference section, for works with up to seven authors, list all authors. For eight authors or more, list the first six, then ellipses followed by the last author's name. Examples of the APA reference style are as follows:

Online/Electronic Journal Article with DOI:

Dikmen, S., Machamer, J., Fann, J. \& Temkin, N. (2010). Rates of symptom reporting following traumatic brain injury. Journal of the International Neuropsychological Society, 16, 401-411. doi:10.1017/ S1355617710000196

\section{Scientific Article:}

Giovannetti, T., Britnell, P., Brennan, 1., Siderowf, A. Grossman, M., Libon, D.J., Seidel, G.A. (2012). Everyday action impairment in Parkinson's disease dementia.
Journal of the International Neuropsychological Society, 18, 787-798.

Book:

Lezak, M.D., Howieson, D.B., Bigler, E.D., Tranel, D. (2012). Neuropsychological Assessment. New York: Oxford University Press.

\section{Book Chapter:}

Mahone, E.M. \& Slomine, B.S. (2008). Neurodevelopmental disorders. In J.E. Morgan, \& J.H. Ricker (Eds.), Textbook of Clinical Neuropsychology (pp. 105-127). New York: Taylor \& Francis.

\section{Report at a Scientific Meeting:}

Weintraub, S. (2012, June). Profiles of dementia: Neuropsychological, neuroanatomical and neuropathologic phenotypes. International Neuropsychological Society, Oslo, Norway.

Manual, Diagnostic Scheme, etc.:

American Psychiatric Association (1994). Diagnostic and Statistical Manual of Mental Disorders (4th ed.). Washington, DC: American Psychiatric Association Press.

English Editing The Research and Editing Consulting Program (RECP) within the International Neuropsychological Society's International Liaison Committee is designed to provide English language editing and statistical consulting to international colleagues who wish to publish their research in English language journals. For additional information see http:// www.the-ins.org/the-research-and-editing-consultingprogram.

Proofs The publisher reserves the right to copyedit manuscripts. The corresponding author will receive PDFs for final proofreading. These should be checked and corrections returned within 2 days of receipt. The publisher reserves the right to charge authors for excessive corrections.

Offprints and PDF Files The corresponding author will receive a free pdf. This pdf can also be mounted on the authors' web pages. Offprints must be ordered when page proofs are returned. The offprint order form with the price list will be sent with your PDF.

Open Access Papers In consideration of payment of the Open Access fee specified by Cambridge University Press, the contribution will be published in the Journal of the International Neuropsychological Society within an Open Access environment, freely accessible to those who wish to browse, read, print, save, copy, display or further disseminate the contribution. Please see the Open Access Transfer of Copyright Agreement for the proper procedures at https://www.cambridge.org/ core/journals/journal-of-the-internationalneuropsychological-society/information/transfercopyright. The processes will depend on your source of funding, permissions to use material owned by an outside source, etc. 


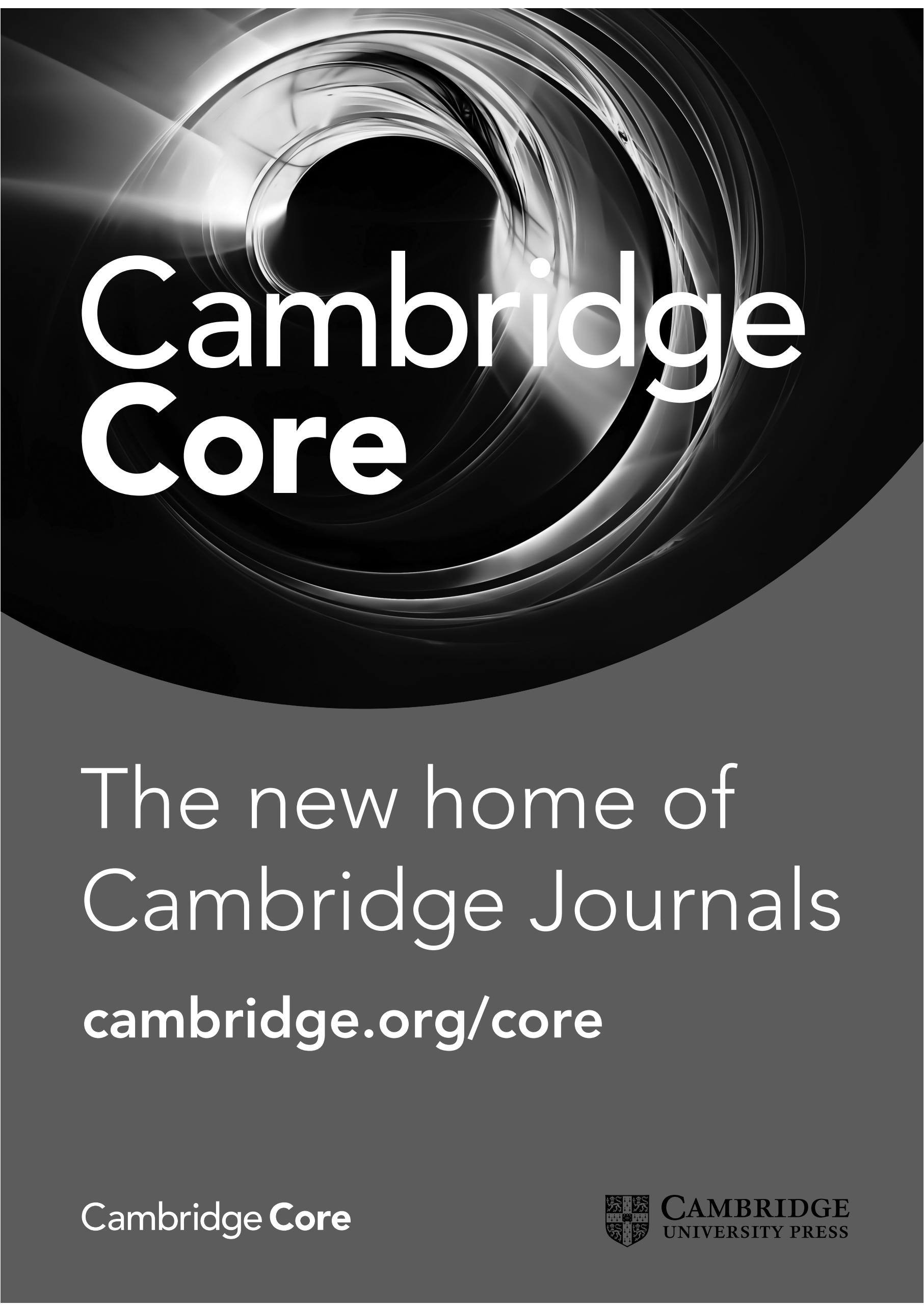




\section{Journal of the International Neuropsychological Society}

Publishing, Advertising, Subscription Offices, and Indexing: Cambridge University Press, One Liberty Plaza, 20th Floor, New York, NY 10006. Telephone: (212) 337-5000; Fax (212) 337-5959. Outside the USA, Canada, and Mexico: Cambridge University Press, The Edinburgh Building, Shaftesbury Road, Cambridge CB2 8RU, England (Telephone: 144(0) 1223 312-393; Fax: 144(0)1223 315-052. For advertising rates and data, contact the Journals Advertising Coordinator at the appropriate Cambridge University Press office. The Journal of the International Neuropsychological Society is covered by the major abstracting and indexing services, including Index Medicus, ISI Current Contents/Clinical Medicine, PubMed, Science Citation Index, SciSearch (also known as the Science Citation Index-expanded), Research Alert, the Neuroscience Citation Index, and PsycInfo.

Subscription Information: Published ten times a year: January, February, March, April, May, July, August, September, October and November. Annual institutional print and electronic subscription rates: US \$1,191.00 in the USA, Canada, and Mexico; UK £681.00 + VAT elsewhere. Institutional electronic rates only: US \$834.00 in the USA, Canada, and Mexico; UK £501.00 + VAT elsewhere. Single part rates: US \$137.00 in the USA, Canada, and Mexico; UK $£ 78.00$ + VAT elsewhere. Prices include surface postage and insurance.

Member Subscription: The Journal of the International Neuropsychological Society is an official publication of The International Neuropsychological Society. Members of the Society automatically receive the Journal of the International Neuropsychological Society as part of their annual membership dues. For further information on membership, please visit the INS website, http://www.the-ins.org. INS office contact: Gordon J. Chelune, Ph.D., Executive Secretary, International Neuropsychological Society, 2319 South Foothill Drive \#260, Salt Lake City, UT 84109. E-mail: INS@utah.edu; Telephone: (801) 487-0475.

Information on Journal of the International Neuropsychological Society and all other Cambridge journals is available via http://www.cambridge.org/ in North America and in the UK. Full text for this journal can be found at http://journals.cambridge.org/.

\section{Copyright $@ 2017$ The International Neuropsychological Society}

All rights reserved. No part of this publication may be reproduced, in any form or by any means, electronic, photocopying or otherwise, without permission in writing from Cambridge University Press, except when permission is obtained through a bona fide copyright clearinghouse, such as the Copyright Clearance Center (USA) or the Copyright Licensing Agency (UK). For further information please visit http://us.cambridge.org/information/rights/. The CCC Item-Fee Code for this publication is 1355-6177/13 \$25.00. Specific written permission must be obtained for all other copying. Photocopying for Classroom Use: Permission to reproduce parts of this publication for course anthologies may be obtained directly from Cambridge University Press or through duly authorized services such as the Academic Permissions Service of the CCC, 222 Rosewood Drive, Danvers, MA 01923 and the Copyright Permissions Service of the National Association of College Stores, or through any photoduplication service that properly secures permission from Cambridge or the CCC.

Periodicals postage paid at New York, NY, and additional mailing offices. Return Postage Guaranteed. Postmaster: Send address changes in the USA and Canada to: Journal of the International Neuropsychological Society, Cambridge University Press, Journals Fulfillment Dept., One Liberty Plaza, 20th Floor, New York, NY 10006.

Printed in the United States of America.

This publication is printed on acid-free paper. 


\section{Journal of the International Neuropsychological Society}

VOLUME 23
NUMBER 1
JANUARY 2017

\section{RESEARCH ARTICLES}

1

Mechanisms of Memory Dysfunction during High Altitude Hypoxia Training in Military Aircrew

11

Relationship of Lutein and Zeaxanthin Levels to Neurocognitive Functioning: An fMRI Study of Older Adults
Oxytocin Reduces Face Processing Time but Leaves Recognition Accuracy and Eye-Gaze Unaffected

Longitudinal Executive Function and Episodic Memory Profiles in Behavioral-Variant Frontotemporal Dementia and Alzheimer's Disease

Mild Cognitive Impairments Moderate the Effect of Time on Verbal Fluency Performance

Neuropsychological Profile of Lifetime Traumatic Brain Injury in Older Veterans

Sex-Related Differences in Emotion Recognition in Multi-concussed Athletes

A Neurophysiological Study of Semantic Processing in Parkinson's Disease

Inhibition and Switching in Healthy Aging:

A Longitudinal Study

Acknowledgements to JINS Guest Editors and External Reviewers, 2016
D.A. Nation, M.W. Bondi, E. Gayles, and D.C. Delis

C.A. Lindbergh, C.M. Mewborn, B.R. Hammond,

L.M. Renzi-Hammond, J.M. Curran-Celentano, and L.S. Miller

K. Hubble, K. Daughters, A.S.R. Manstead, A. Rees,

A. Thapar, and S.H.M. van Goozen

S. Ramanan, M. Bertoux, E. Flanagan, M. Irish, O. Piguet,

J.R. Hodges, and M. Hornberger

E. Demetriou and R. Holtzer

A.R. Kaup, C. Peltz, K. Kenney, J.H. Kramer,

R. Diaz-Arrastia, and K. Yaffe

E. Léveillé, S. Guay, C. Blais, P. Scherzer, and L. De Beaumont

A.J. Angwin, N.N. Dissanayaka, A. Moorcroft, K.L. McMahon, P.A. Silburn, and D.A. Copland

S. Adólfsdóttir, D. Wollschlaeger, E. Wehling, and A.J. Lundervold 